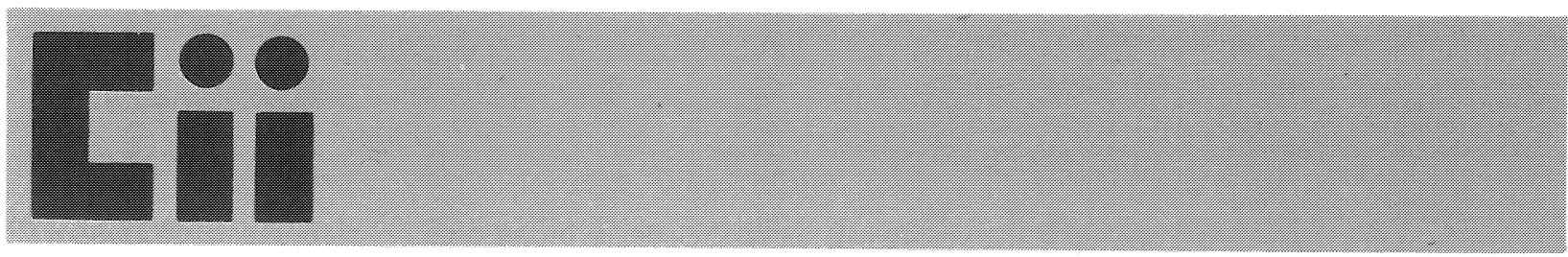

\title{
PROYECTOS DE PARCELAS CON SERVICIOS DESARROLLADOS POR EL INVI EN LA REPUBLICA DOMINICANA
}

\author{
(PROJECTS FOR PLOTS OF LAND PROVIDED WITH SERVICES, \\ DEVELOPED BY INVI IN THE DOMINICAN REPUBLIC)
}

Carlos Pou Howley, Arquitecto

Encargado DIPRO (INVI)

REPUBLICA DOMINICANA

\section{RESUMEN}

Santo Domingo, capital de la República Dominicana, no ha escapado al fenómeno del crecimiento urbano y a la concentración de grandes tugurios o arrabales, debido principalmente a los movimientos migratorios de los campesinos expulsados del campo.

Como una solución viable al gran problema de la vivienda de esta ciudad, el INVI, con la participación del Banco Mundial, plantea proyectos de parcelas con Servicios en los cuales se instalan servicios de infraestructura en tierras urbanas y se proporcionan parcelas o solares a familias para que éstas construyan o completen sus viviendas.

Se ubican estos proyectos en sitios que acusan una mayor tendencia de desarrollo. El esquema urbano, planteado en ambos proyectos, es de carácter eminentemente peatonal y tienen una reducida red vial vehícular. En la red peatonal se logró el emplazamiento de lo que se ha denominado mini-parques y que consisten en el ensanchamiento del camino peatonal que, además de ser áreas verdes distribuidas en los proyectos, se refuerza la idea de vecindario.

Por la envergadura de los proyectos, han sido previsto una serie de instalaciones para mantener servicios comunitarios propios, asi como comerciales $e$ institucionales distribuidos estratégicamente.

\section{INTRODUCCION}

\subsection{Antecedentes generales del país}

La República Dominicana es un pais de escasa extensión territorial tiene aproximadamente 48,400 kilómetros cuadrados (equivalente a poco más del doble de la provincia española de Badajoz o 6 veces la superficie de la provincia de Madrid); ocupa las dos terceras partes orientales de la Isla de Hispaniola; la otra parte en el sector occidental es la República de Haití. La isla está separada de Cuba en el oeste por el Pasaje de Barlovento y de Puerto Rico al este por el Pasaje de Mona. Al norte se encuentra el Océano Atlántico y al sur, el Mar Caribe.

La parte occidental del pais se ve dominada por cuatro cordilleras, la mayor de las cuales, la Cor-

\section{SUMMARY}

Santo Domingo, the capital of the Dominican Republic, has not escaped the phenomenon of urban growth and the concentration of large slum areas or hovels, mainly due to the migratory movements of the peasants who have been driven from the country.

As a viable solution to the enormous problem of housing in this city, INVI, with the participation of the World Bank, is putting forward projects for lots supplied with services in which infrastructure services are installed on urban land and plots or parcels of land are given to families so that they can build or complete their houses.

These projects are located in places registering a greater tendency towards development. The urban plan formulated in both projects is of an eminently pedestrian nature with a reduced thoroughfare for vehicles. In the pedestrian precinct, it was possible to lay down what have been called mini-parks, which involve widening the pedestrian thoroughfare and, in addition to constituting green areas distributed throughout the projects, they also reinforce the idea of a neighbourhood.

Because of the scope of the projects, a series of installations have been provided to maintain their own community services, as well as commercial and institutional ones, which are distributed strategically. dillera Central, se extiende hacia el oeste a Haiti y divide la isla en mitades. La región agricola más vasta y fértil se encuentra en el Valle de Cibao, en la parte central y norte de la República. Existen varios ríos especialmente debajo de la cuenca hidrográfica de la Cordillera Central, y proporcionan una fuente de agua disponible para el riego y la producción de energía hidroeléctrica. El resto del pais es mayormente plano y fértil.

Dada su variada topografía, el pais ofrece una diversidad de climas.

Las tierras dedicadas a la agricultura, representan alrededor del 22,4\% del área total; la ganadería ocupa un $21,6 \%$ y los bosques y reservas territoriales representan aproximadamente el $55.4 \%$ del área total. El resto consiste en lagos y tierras no aprovechables. 
El crecimiento demográfico del pais, constituye uno de sus principales problemas; la población estimada en 1981 fue de 5.6 millones de habitantes, localizada un $52 \%$ en las zonas urbanas y 48 por 100 en las zonas rurales, con una densidad de 117 habitantes por km2, superior a la mayoria de los paises lberoamericanos.

La tasa de crecimiento demográfico anual nacional, es del $2,9 \%$, se urbaniza aceleradamente a un ritmo de $5,2 \%$ y se concentra en las ciudades mayores de 30.000 habitantes y en especial en Santo Domingo, la ciudad Capital.

Esta tasa de crecimiento urbano se ha acentuado por una marcada migración del sector rural hacia el urbano, debido a las diferencias urbano-rurales en cuanto a condiciones generales de vida, ingresos y oportunidades de empleo.

La población es joven, el 47,55 \% tiene menos de 14 años y presenta un alto nivel de dependencia. La población económicamente activa, se estima en 1,9 millones de las cuales un $25 \%$ se encuentra desempleado y un $50 \%$ en sub-empleos, siendo la situación más grave en las zonas rurales y entre las mujeres y jóvenes.

La población en general está afectada por una mala distribución de los ingresos. El $50 \%$ tiene ingresos minimos, el $31,8 \%$ ingresos bajos, el $12,5 \%$ medios y el 5,4 altos. Presenta asimismo, un alto grado de analfabetismo (36\%) y bajo nivel de instrucción, producto de una insuficiente cobertura en todos los niveles de educación.

Asimismo, la cobertura de salud es deficitaria, principalmente en el sector rural $y$ aunque se ha avanzado en los últimos años, sigue siendo escasa.

\subsection{PROBLEMA DE LA VIVIENDA}

El inventario de viviendas alcanza 1.1 millones $y$ se estima un déficit cualitativo de 400,000 unidades.

La vivienda y servicios habitacionales son aspectos importantes en la calidad de vida y muy especialmente para las familias de bajos y minimos ingresos. Una estimación conservadora de las necesidades de servicios habitacionales para los próximos 20 años que cubre el aumento vegetativo, parte del déficit de necesidades por obsolescencia y cambio de uso del inventario, da una cifra cercana a las 63.000 viviendas y/o soluciones promedio anual, de las cuales más del $60 \%$ deben ser producidas para los sectores de más bajos ingresos.

Enfrentar este enorme desafío demanda de toda la capacidad creadora de la comunidad nacional, asi como de la incorporación al proceso de desarrollo de estos mismos sectores en proyectos de amplia participación de la comunidad, a fin de incentivar la participación popular en el desarrollo de proyectos que satisfagan sus necesidades básicas.

\subsection{EL INSTITUTO NACIONAL DE LA VIVIENDA}

El Instituto Nacional de la Vivienda (INVI), es un organismo autónomo, creado el 10 de mayo, 1962, destinado a producir servicios habitacionales para los sectores de menores ingresos, urbanos y rurales, formular políticas y programas nacionales de viviendas, dar asistencia a grupos organizados para la producción habitacional y promover la construcción de viviendas por Esfuerzo Propio.

EI INVI como organismo rector del sector vivienda y asentamientos humanos es el principal ejecutor de la producción de soluciones habitacionales del país. En sus 22 años de vida institucional, se puede distinguir las siguientes etapas en su desarrollo.

\section{PRIMERA ETAPA (1962 - 1965)}

La producción del INVI en este periodo fue de 2.176 unidades habitacionales, atendiendo 30 localidades del pais con una inversión aproximada de 4 millones de pesos (aproximadamente $4 \mathrm{mi}$ llones de dólares). Con un promedio de producción anual de 544 viviendas. También se iniciaron en este período relaciones con otras instituciones del Estado, entre las que se destacan las del Instituto Agrario Dominicano, para la construcción de viviendas en el área rural para los beneficiarios de la Reforma Agraria.

\section{SEGUNDA ETAPA (1966 - 1978)}

Este periodo de 12 años de vida institucional, se inicia después de la Guerra de abril (intervención y ocupación de tropas norteamericanas), y durante el cual el Instituto ejecutó algunos proyectos de remodelación urbana.

Hubo una gran multiplicidad de organismos públicos que además de sus funciones propias se dedicaron a la construcción de viviendas, y esto trajo como consecuencia un estancamiento en el desarrollo institucional del INVI. La producción de viviendas del INVI durante este periodo, alcanzó la cifra de 5.020 viviendas, con una inversión de 22 millones de pesos (aproximadamente 22 millones de dólares), lo que determinó una baja producción de 386 viviendas por año.

\section{TERCERA ETAPA (1979 - 1982)}

Este periodo se caracteriza por las nuevas directrices entregados por el Gobierno para reorientar las 
actividades de los sectores construcción y vivienda, Io que ha permitido al INVI ejercer con mayor plenitud las facultades otorgadas por la ley.

Para cumplir con sus tareas e implementar las nuevas directrices de política, el INVI inicia un proceso de fortalecimiento institucional, adecuando su estructura organizativa y confeccionando los instrumentos técnicos de operación. Al cumplimiento de esta tarea, se suma un nuevo desafío a consecuencia de los efectos desvastadores de los huracanes "David" y "Federico", que en el año 1979 azotaron la zona oeste del pais y destruyeron unas 100.000 viviendas.

Para superar esta enorme tarea con escasos medios disponibles, el INVI incorporó en sus programas habitacionales la participación y los recursos de la comunidad y la adopción de nuevas tecnologías. Es así como se ejecutan los programas de emergencia y reconstrucción utilizando el sistema de "Ayuda Mutua" y "Esfuerzo Propio", con la incorporación de las familias afectadas, que en un número superior a las 40.000 pudieron reconstruir sus hogares.

Es importante señalar, que en algunos programas el INVI ha empleado en varios casos, tecnologias apropiadas para su ejecución, en las que se utilizan materiales y recursos locales.

Asimismo, se han emprendido programas, con otorgamiento de créditos en materiales a las familias participantes; también se ha programado dos proyectos de parcelas con servicios (uno de los cuales, con 4.600 parcelas se ha iniciado recientemente en el Distrito Nacional y que desarrollamos más adelante).

\section{CUARTA ETAPA (1982 - 1984)}

En este período que comprende los últimos dos años de vida institucional, el INVI ha continuado con su fortalecimiento institucional para dar cumplimiento con sus objetivos recuperando el rol que la ley le asigna, como director del sector y se avoca a formular las políticas, planes y programas del sector vivienda. Esto en forma paralela a su propósito de producir soluciones habitacionales de bajo costo para los sectores de menores ingresos del pais.

Como se comprenderá, pasar de una producción anual de 500 viviendas a una de 20.000 viviendas (y/o soluciones habitacionales) planteado como meta en la estrategia del sector, para un periodo más amplio que el señalado (1982-1986), requiere una acción extraordinaria. El propósito no sólo ha sido disminuir el déficit habitacional, sino también reactivar el sector de la construcción y generar rápidamente más empleos.

\subsection{CAPACIDAD CONSTRUCTIVA DE LOS SEC- TORES POPULARES Y EL CRECIMIENTO DE SANTO DOMINGO}

La gran mayoria de las viviendas o soluciones habitacionales, existentes en el país, son el producto de los llamados sectores informales o populares. En el periodo $1960-1970$, el $85 \%$ del total de 120.000 viviendas producidas en el pais fue el producto de los sectores informales y el $15 \%$ restante (21.000 viviendas) lo produjo el sector formal.

En el decenio de 1970-1980, la participación de los sectores populares alcanzó el $78 \%$ de la producción total estimada en 270.000 viviendas, (10 cual representa una producción de 211.500 viviendas) y el $22 \%$ restante ( 58.700 viviendas) es la producción de los sectores formales (sectores públicos y privados). En la actualidad, la participación de los sectores informales se estima en superior al $85 \%$.

Esta capacidad de ejecución mostrada por los sectores populares ha permitido a las familias de escasos recursos resolver con sus propios medios sus problemas habitacionales invirtiendo sus escasas economias monetarias, la disponibilidad de mano de obra y la reutilización de materiales de desecho. Esta es una producción sin asistencia técnica ni control y es la causa principal del déficit cualitativo que el inventario de viviendas y del desordenado crecimiento urbano de las ciudades del país.

El crecimiento urbano y la creación de grandes concentraciones de tugurios 0 arrabales, que se ha venido desarrollando en toda Iberoamérica, no ha sido una excepción en República Dominicana, donde el crecimiento general de la población es del $6 \%$ anual y los barrios marginados crecen en casi el doble de este porcentaje.

Este fenómeno es nuevo en América Latina y aparece con verdadera fuerza en la década de los 50 y se debe principalmente a los movimientos migratorios de los campesinos expulsados del campo, las familias campesinas abandonan el campo y prefieren instalarse en forma infrahumana en los terrenos desechables de las grandes ciudades, formando un verdadero "sub-mundo de miseria, atraso, insalubridad, y analfabetismo". Construyen sus "tugurios o conventillos" en Argentina, sus "corralones o callejones" en el Perú, las "callampas" en Chile, y las "favelas" en el Brasil, llamadas asi cuando se insertan en el casco urbano existente. Aparece también, la creación de "ciudades espontáneas" y estos asentamientos nacen y se reproducen con extraordinaria rapidez en las faldas de los cerros. (en Caracas, Bogotá, Valparaiso, Lima y Río), en las márgenes anegadizas (Santo Domingo, Bahia, Recife) o en las grandes zonas suburbanas de ciudad México, Buenos Aires o Santiago de Chile. 
Estos asentamientos se llaman "cantegriles" en Uruguay, "villas miserias" en Argentina, "pueblos jóvenes" o "barriadas" en Perú, "campamentos" 0 "poblaciones" en Chile, o "ranchitos" en Venezuela. $Y$ en ellos se albergan millones de familias de emigrantes rurales principalmente y "sublevados" de barrios bajos que ocupan terrenos ilegalmente. Estos asentamientos se han convertido con el paso de los años, en verdaderas "ciudades" dentro de las ciudades y los gobiernos han tenido que oficializarlos, dándoles los servicios mínimos de infraestructura.

Es asi y dentro de este marco general, que en República Dominicana, en 1960 Santo Domingo asentaba al $12 \%$ de la población del país en 1970 este porcentaje era del $23 \%$, en 1981 habia subido al 27,5\% esperándose que para 1990 esta cifra sea superior al $30 \%$.

Gran parte de la población de la Capital, vive en "barrios marginales" y se estima que actualmente el $75 \%$ de sus habitantes llevan una vida precaria en estos sectores marginales. Por otra parte, se ha demostrado que el $90 \%$ de estas personas son provenientes de zonas rurales.

\section{PROYECTOS DE PARCELAS CON SERVICIOS}

\subsection{GENERALIDADES}

Como se ha expresado anteriormente, el INVI en 1980 inició los estudios de dos anteproyectos de parcelas con servicios. Se ha contado con la participación financiera del Banco Mundial y en la actualidad el Instituto ha iniciado uno de ellos, el denominado Sabana Perdida.

Los proyectos de Parcelas y Servicios en los cuales se instalan servicios de infraestructura en tierras urbanas y se proporcionan pequeñas parcelas a familias de escasos recursos para que éstas construyan o completen sus propias viviendas, creemos que son apropiados para la creación de comunidades de bajos ingresos. Es por esto que queremos presentar este tipo de proyecto como una solución viable al gran problema de la vivienda en los países de Iberoamérica, en los cuales los gobiernos no tienen los recursos minimos indispensables para abordarlo. Recuérdese, que en Iberoamérica faltan 50 millones de viviendas y que en el año 2000 habrá 510 millones de habitantes urbanos, de los cuales el $50 \%$ vivirán en uranchitos" o "chabolas".

\subsection{ASPECTOS TECNICOS DE LOS PROYECTOS SABANA PERDIDA Y HAINA}

\subsection{GENERALIDADES}

Como todas las grandes ciudades iberoamericanas, Santo Domingo ha experimentado en los últi- mos 20 años fuertes crecimientos hacia determinadas zonas de su periferia, debido principalmente a la disponibilidad de terrenos adecuados y al desarrollo de algunas nuevas fuentes de trabajo. Los sitios seleccionados para la ubicación de los proyectos mencionados, se encuentran precisamente entre los que acusan una mayor tendencia de desarrollo. En el caso del Proyecto Sabana Perdida, influye la cercanía de zonas industriales (Los Mina y Máximo Gómez) y la propuesta Zona Industrial Los Mina-Sabana Perdida. En el caso del Proyecto Haina, la cercanía con la Zona Industrial, el Central Azucarero, la Refinería de Petróleo y la ampliación del muelle, el más importante del pais. (Ver plano general $n .^{\circ} 1$ ).

El esquema urbano planteado en ambos proyectos, es de carácter eminentemente peatonal en su trazado y tiene una reducida 'red vial vehicular. Esta red vehicular está compuesta por dos tipos básicos de vías: a) Una principal que funciona como entrada y salida al proyecto y que conecta fundamentalmente los accesos con la zona central de servicios comunales y b) Secundarias a modo de cul-de-sac que partiendo de la vía principal penetran y dan acceso a zonas habitacionales. Se ha considerado estacionamientos para vehículos a razón de un puesto por cada 30 parcelas.

En la red peatonal, se han creado mini-parques, que consisten en el ensanchamiento del caminc peatonal convencional. Los miniparques constituyen una modalidad diferente de parque, ya que además de ser áreas verdes distribuidas en el proyecto, son zonas de acceso a las viviendas. Los caminos peatonales sirven a la vez como jardines comunes para un grupo de familias con lo que reforzamos la idea de vecindario, existente entre las clases populares y que incentiva la vida en comunidad.

Debido a que las comunidades de ambos proyectos serán lo suficientemente grandes (17 y $25 \mathrm{mil}$ habitantes respectivamente, que corresponden a verdaderas ciudades intermedias en República Dominicana) para demandar y mantener servicios comunitarios propios, se han previsto en ambos proyectos una serie de instalaciones para tales fines. En la forma del esquema urbano, se han distribuido en dos núcleos generadores de actividades y movimientos en función de su utilización.

Uno de estos núcleos es el centro comercial y el otro es el de las actividades comunales e institucionales en el que estará ubicado un centro de salud, una escuela, estafetas de pago, una estación de bomberos y un destacamento policial.

Además, se ha dispuesto varios centros vecinales distribuidos estratégicamente dentro de cada proyecto, los cuales juegan un rol importante dentro del esquema organizativo de la comunidad funcionando como los centros primarios de aglutinamiento. 


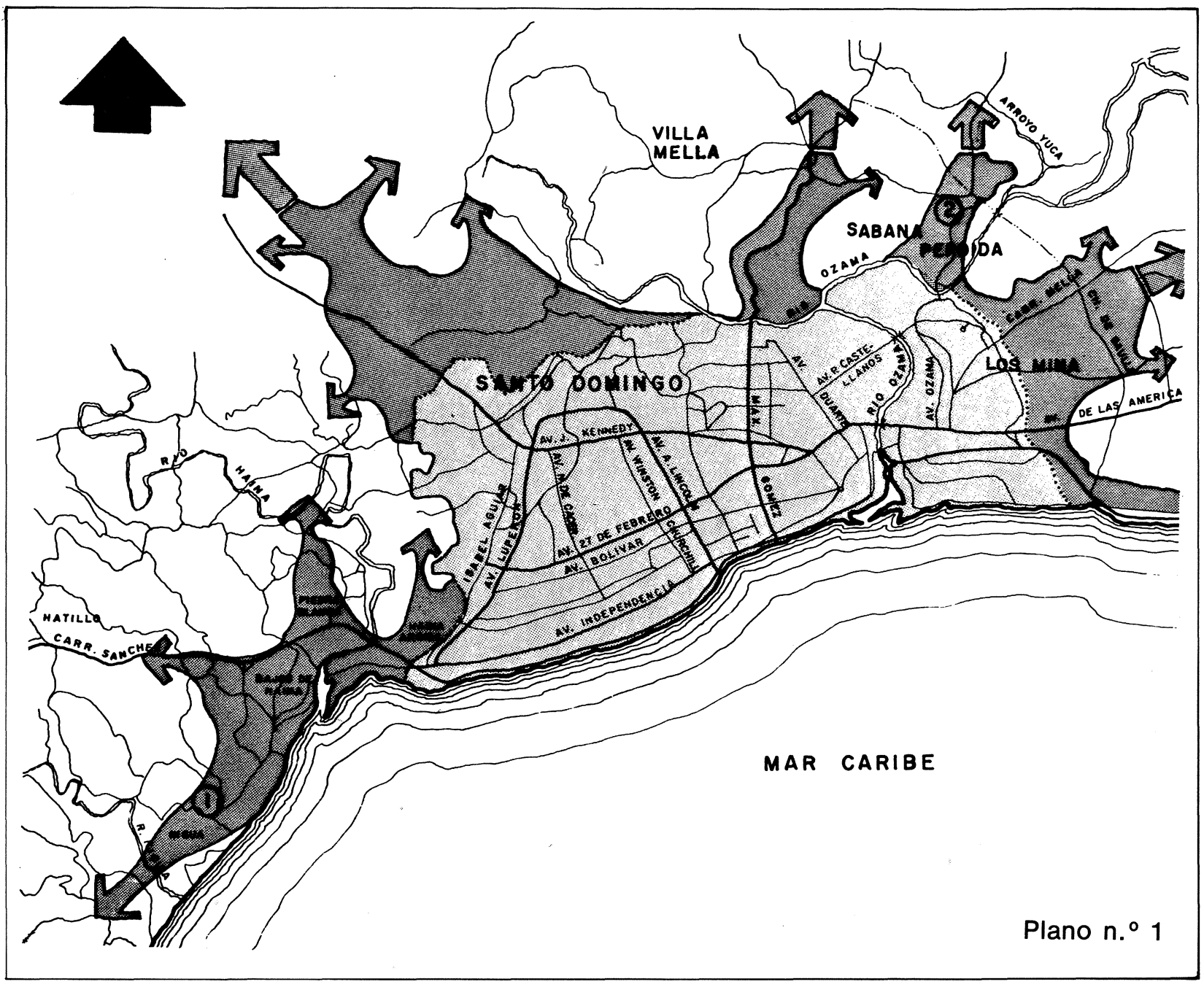

\subsubsection{PROYECTO DE PARCELAS Y SERVICIOS SABANA PERDIDA}

El proyecto Sabana Perdida, se encuentra al Noreste de la ciudad (según señala en el plano $n .^{\circ} 1$ ), en el sector denominado Majagual de Sabana Perdida. Su entorno inmediato lo constituyen un pequeño poblado existente denominado Sabana Perdida, el barrio de El Milloncito, las cuencas y zonas bajas del Arroyo Yuca y el Río Ozama y la Carretera a La Victoria.

El área de terreno a desarrollar es de 82 hectáreas útiles, de las cuales se han destinado para área de viviendas 50,8 hectáreas $(62,3 \%$ de la superficie total). Se ha proyectado 4.656 parcelas de aproximadamente $100 \mathrm{~m}^{2}$ cada uno.

El uso del suelo es el siguiente:

\begin{tabular}{|lcr|}
\hline & A rea (has) & $\%$ \\
\cline { 2 - 3 } & & \\
Area total de terreno & 91,58 & - \\
Area útil & 81,53 & 100,00 \\
Area de protección & 10,94 & 12,32
\end{tabular}

Area de circulación:

\section{Vehicular \\ Peatonal \\ Estacionamientos}

Areas verdes

Area comunal y servicios

Area habitacional

Area comercial

N. ${ }^{c}$ de parcelas

Población

Densidad Bruta

Densidad Neta

Solar tipo:

$6,256 \mathrm{~m} \times 16,66 \mathrm{~m}=(104,37 \mathrm{~m} 2)$
4.656 Uds.

25.780 habitantes

$316,18 \mathrm{hab} / \mathrm{has}$

$477,80 \mathrm{hab} / \mathrm{has}$
Se ha considerado la infraestructura completa del proyecto, es decir, se contempla suministro de agua, evacuación de aguas negras (alcantarillado sanitario con planta de tratamiento), alcantarillado aguas pluviales, suministro y distribución de energía eléctrica, además de la vialidad ya descrita. 


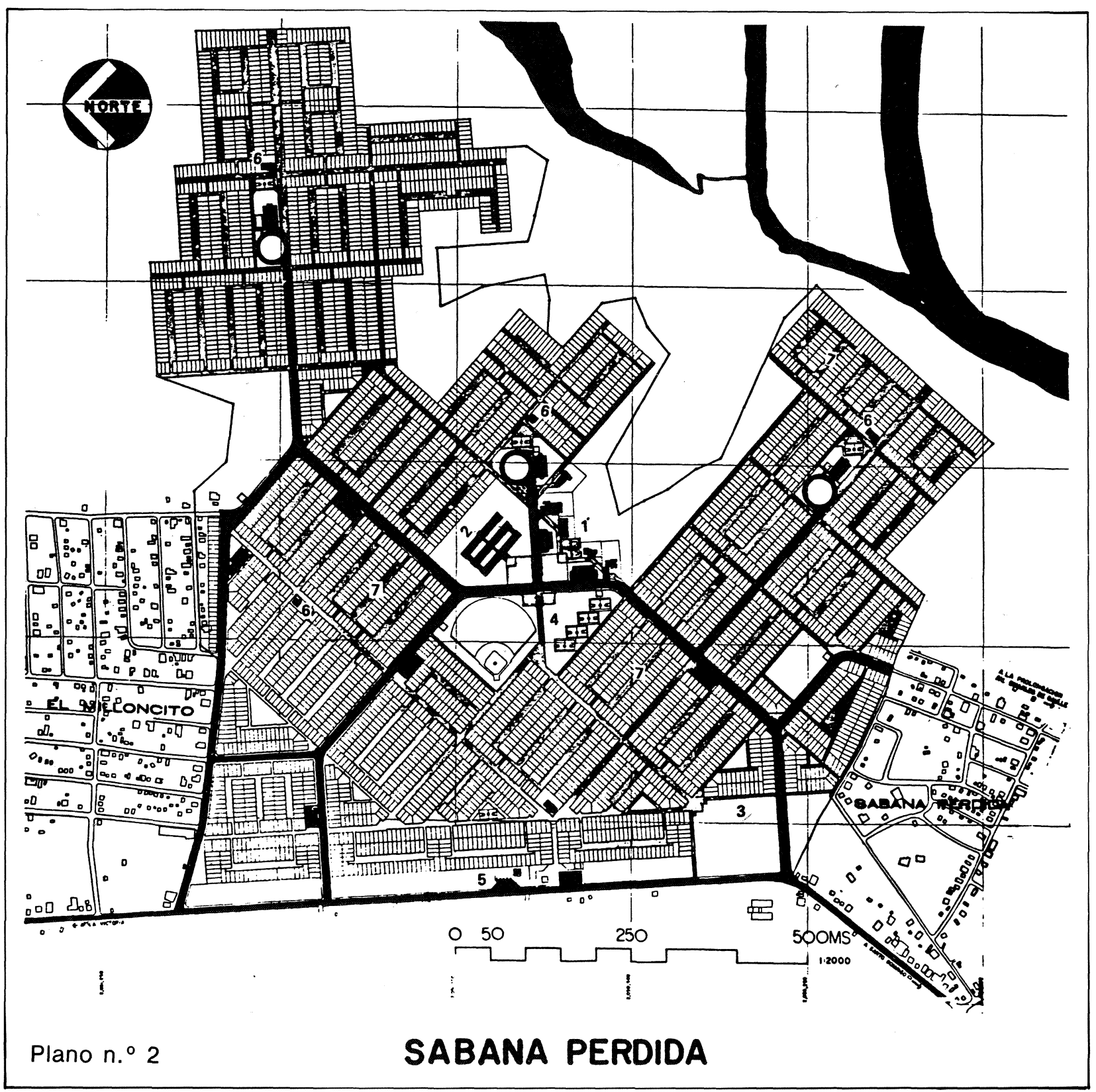

El desarrollo del proyecto ha sido planteado en cuatro etapas:

a) Una primera etapa al lado de la carretera a La Victoria con 1.216 unidades, que abarca una superficie de 22,99 has. Se ha proyectado en ella, el centro comercial, un centro vecinal $y$ el parque deportivo.

b) Una segunda etapa colindante con el barrio marginal El Milloncito de 1.318 unidades, abarca un área de 27,37 has. Esta etapa cuenta con los servicios de una escuela primaria, el centro comunal y dos centros vecinales.

c) Una tercera etapa vecina al poblado existente de Sabana Perdida, tiene 992 unidades en un área de 17,51 has. Cuenta con una escuela primaria, un centro vecinal; y d) Una cuarta etapa bordeada por ríos y cañadas en el extremo Este del proyecto con 1.130 unidades dentro de un área de 16,39 has. Cuenta con un centro vecinal.

\section{PROYECTO DE PARCELAS Y SERVICIOS HAINA}

El proyecto Haina se encuentra ubicado al Suroeste de la ciudad de Santo Domingo enfrente del poblado de Nigua en la Provincia de San Cristóbal. Su entorno inmediato lo constituyen el poblado de Nigua, ubicado al Sur y separado tan sólo por la antigua carretera Sánchez al Noroeste el poblado de Bajos de Haina, la Zona Industrial y la Refinería de Petróleo. (Ver plano N. ${ }^{\circ} 1$ ).

El área de terreno es de unas 55 has., útiles de las cuales se han destinado para área de viviendas 
el $62,7 \%$ (equivalente a 34,75 has.) divididas en 3.277 parcelas de aproximadamente $100 \mathrm{~m} 2$ de superficie cada uno.

La entrada principal al proyecto ha sido ubicada desfasada con relación al cruce de Nigua para evitar posibles conflictos de circulación y de identificación entre ambos hitos de referencia urbana, aunque a través del centro comercial se integra el proyecto a la actividad comercial del cruce. Se ha previsto otro acceso vehícular desde la Carretera Sánchez y se dejó previsto en la parte Noroeste del proyecto el empalme con una vía que lo enlazaría con la Zona Industrial de Haina.

Las áreas dedicadas a zonas verdes y parques en el proyecto, representan el $17,04 \%$ del total del área útil, distribuidas en parques deportivos, parques urbanos y mini-parques.

El área comercial ha sido proyectada como un Centro Comercial concentrado que ocupa un área de terreno de 1,25 has.
La infraestructura interna del proyecto la constituirá un acueducto completo que incluye lineas de distribución, acometidas domiciliarias y un depósito.

La evacuación de las aguas negras se realizará mediante la construcción de un alcantarillado sanitario que descargará a través de un colector general en una planta de tratamiento primario.

La recolección de las aguas de lluvias, se realizará a través de un alcantarillado pluvial con pozos filtrantes en las zonas bajas.

El sistema de suministro y distribución de energía eléctrica, consistirá básicamente en un ramal primario. El desarrollo del proyecto ha sido concebido en tres etapas, habiéndose tomado en consideración para su división las mismas premisas que para el proyecto Sabana Perdida.

a) Una primera etapa al lado de la antigua Carretera Sánchez de 1.049 unidades que abarca una extensión de terreno de 18,18 has. Dentro

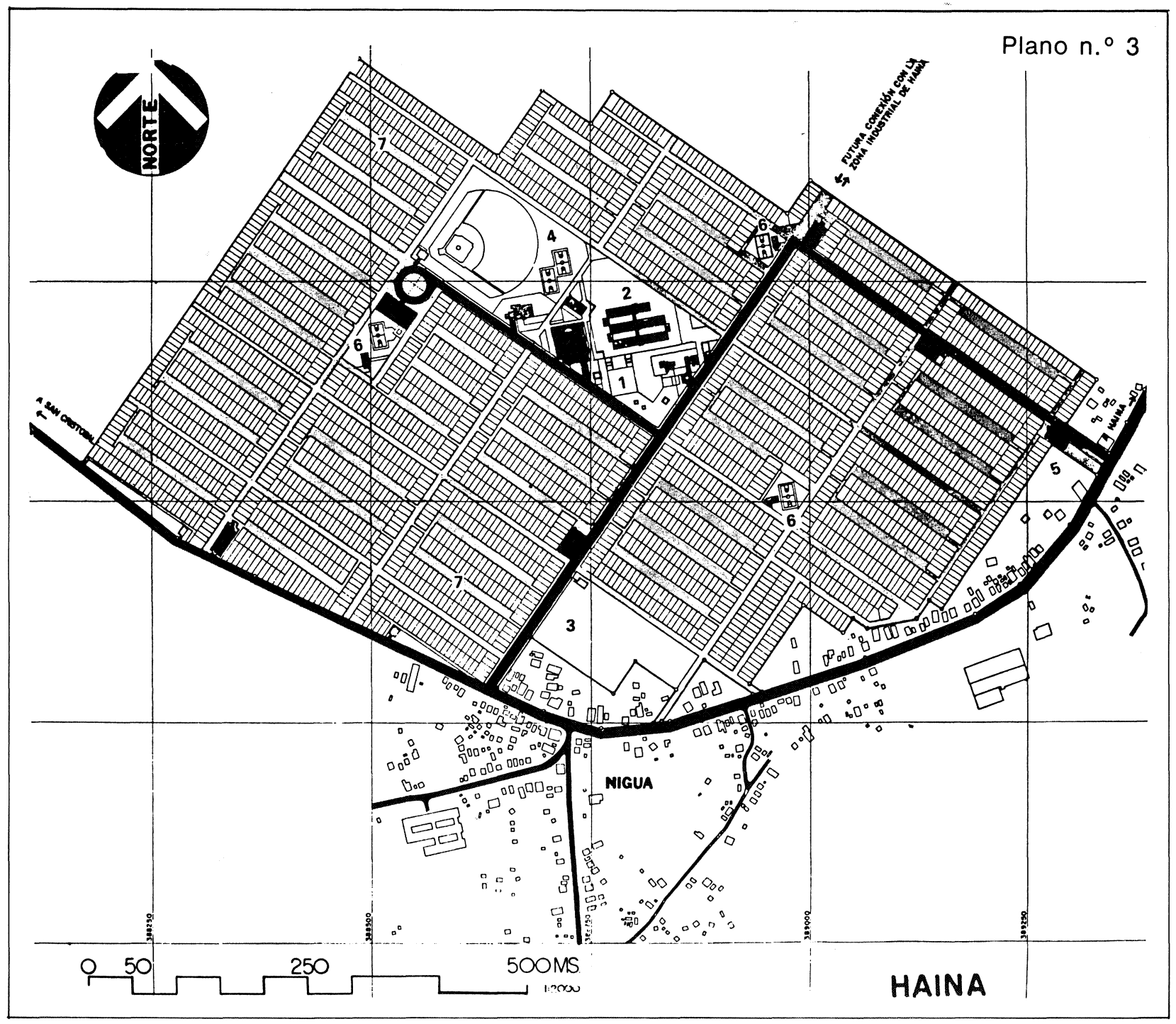


de la misma se encuentra un centro vecinal y un centro comercial.

b) una segunda etapa también al lado de la Carretera y que se inicia frente al cruce de Nigua de 1.309 unidades abarcando una extensión de terreno de 24,34 has. Esta etapa contará con los servicios de centro comunal completo centro deportivo y un centro vecinal; $y$

c) Una tercera etapa en la parte norte del proyecto y bordeada por cañadas con 869 unidades dentro de un área de 12,93 has. Cuenta con los servicios de un centro vecinal.

\begin{tabular}{|lcc|}
\hline & Area (Has.) & $\%$ \\
\cline { 2 - 3 } & 55,44 & 100,00 \\
Area total de Terreno & 55,44 & 100,00 \\
Area útil & - & - \\
Area de Protección & & \\
Area de Circulación & 1,23 & 2,23 \\
$\quad$ Vehicular & 6,31 & 11,39 \\
$\quad$ Peatonal & 0,56 & 1,02 \\
$\quad$ Estacionamientos & 9,44 & 17,04 \\
Areas verdes & 1,88 & 3,40 \\
Area comunal y Servicios & 34,73 & 62,66 \\
Area Habitacional & 1,25 & 2,26 \\
Area comercial & 3.227 Unidades \\
N. de parcelas & 17.868 Habitantes \\
Población & 322,24 hab/has. \\
Densidad Bruta & 514,24 hab/has. \\
Densidad Neta & \multicolumn{2}{l}{} \\
Solar tipo: & \multicolumn{2}{l}{} \\
6,20 m x 16,40 m $=\left(101,68 \mathrm{~m}^{2}\right)$. & \\
\hline
\end{tabular}

\subsubsection{LA VIVIENDA}

En el proyecto original se plantearon sólo dos modelos de viviendas (que se señalan en los planos adjuntos como tipos $A$ y B). En la presente administración se han incluido los modelos $C$, $D, E$ y $F$ en busca de menores costos.

Todos estos modelos, son soluciones o viviendas pareadas con callejón lateral. Los ambientes han sido modulados atendiendo al tamaño de los bloques que serán usados en la construcción de sus paredes y la cubierta es una losa de hormigón en los modelos A y $B$ y cerchas de madera y zinc en los modelos C, D y E.

El callejón lateral, es una caracteristica tradicional en la vivienda popular dominicana mediante el cual se favorece la ventilación interior a la vez que se da acceso directo al patio, ubicado en la parte trasera de la vivienda.

\section{MODELO «A»}

Tiene dos cuerpos dispuestos uno al frente y otro al fondo del solar, separados por un patio central

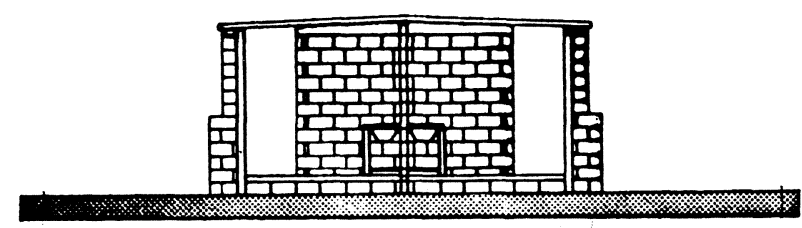

\section{ELEVACION FRONTAL}
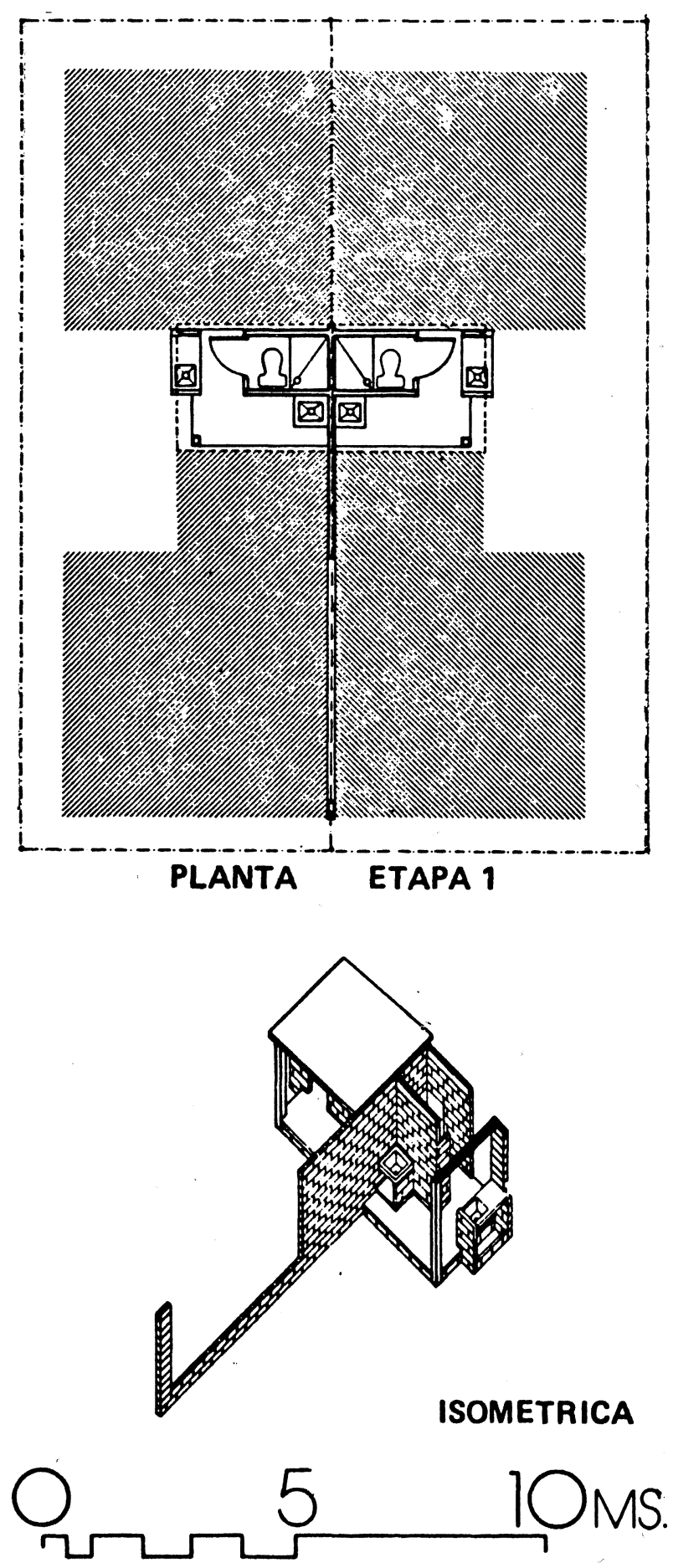

MODELO A 


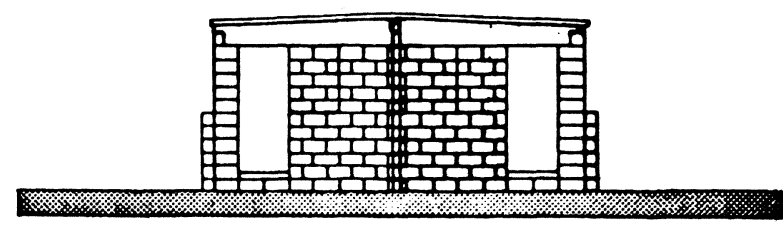

ELEVACION FRONTAL

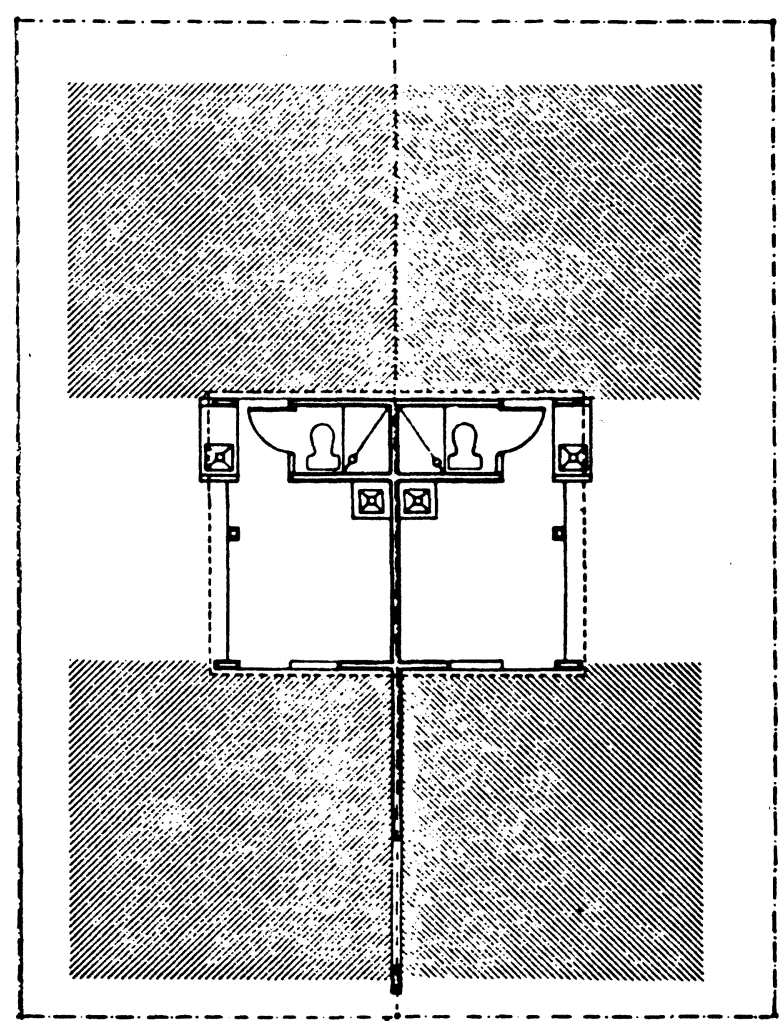

PLANTA

ETAPA 2

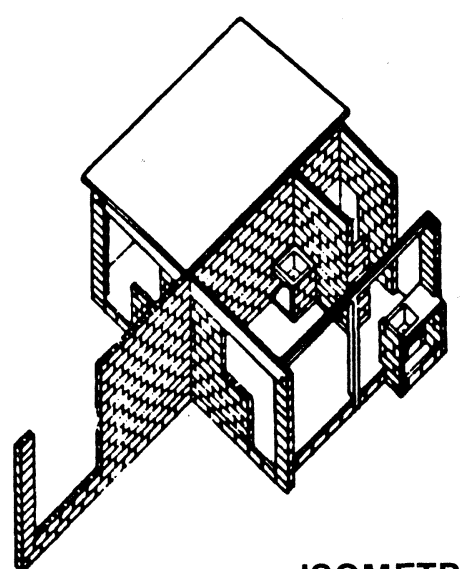

ISOMETRICA

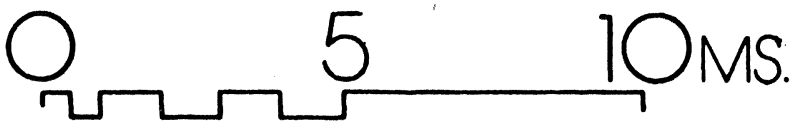

MODELO A y por el núcleo de servicios. El núcleo de servicios, consiste en un área techada con uno de sus lados abiertos al patio en el que se encuentra el baño, la cocina y el comedor.

Su desarrollo se producirá en cuatro etapas sucesivas de desarrollo progresivo como sigue.

\section{ETAPA 1}

Tiene un área de $7,16 \mathrm{~m}^{2}$, con un $7 \%$ de ocupación del terreno.

Consiste en una unidad sanitaria compuesta de ducha, inodoro, lavadero y fregadero. Está ubicada prácticamente en el medio de la parcela para que sirva de punto de partida al desarrollo progresivo de la vivienda.

\section{ETAPA 2}

Su área de construcción techada es de $12,60 \mathrm{~m}^{2}$, con un $12,3 \%$ de ocupación de terreno.

\section{ETAPA 3}

Su área de construcción es de $28,60 \mathrm{~m} \cdot{ }^{2}$ con un porcentaje de ocupación de terreno de $28 \%$. Es la unidad básica que consiste en una pequeña unidad habitacional con la unidad sanitaria más una pequeña área cerrada. Es la primera solución en que la familia puede habitar de inmediato.

\section{MODELO «B»}

Se ha diseñado con criterios similares al Modelo "A" con la diferencia de que en éste la etapa 1 es aislada (según se demuestra en los planos adjuntos). Los materiales usados son los mismos, es decir, muros de bloques de hormigón y techo de losa.

\section{ETAPA 1}

Superficie $11,1 \mathrm{~m}^{2}$ de construcción que representan al 10,90\% de ocupación del terreno. Al igual que en el Modelo "A", consiste en una unidad sanitaria compuesta de ducha, inodoro, lavadero y fregadero. Está ubicada prácticamente en el centro de la parcela.

\section{ETAPA 2}

Tiene una superficie construida de $19,20 \mathrm{~m}^{2}$, con un $18,80 \%$ de ocupación del terreno.

\section{ETAPA 3}

Area de 25,60 $\mathrm{m}^{2}$ con una ocupación del terreno del 25,1 \%. La unidad básica, similar a to mencionado en el Modelo "A". 


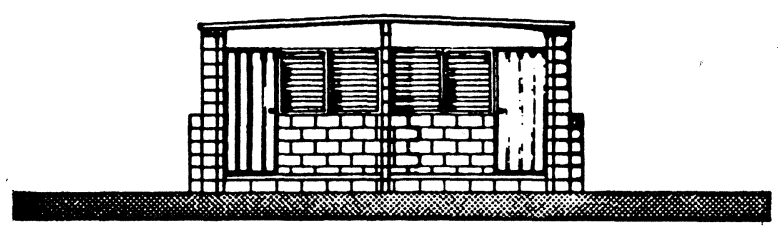

\section{ELEVACION CENTRAL}

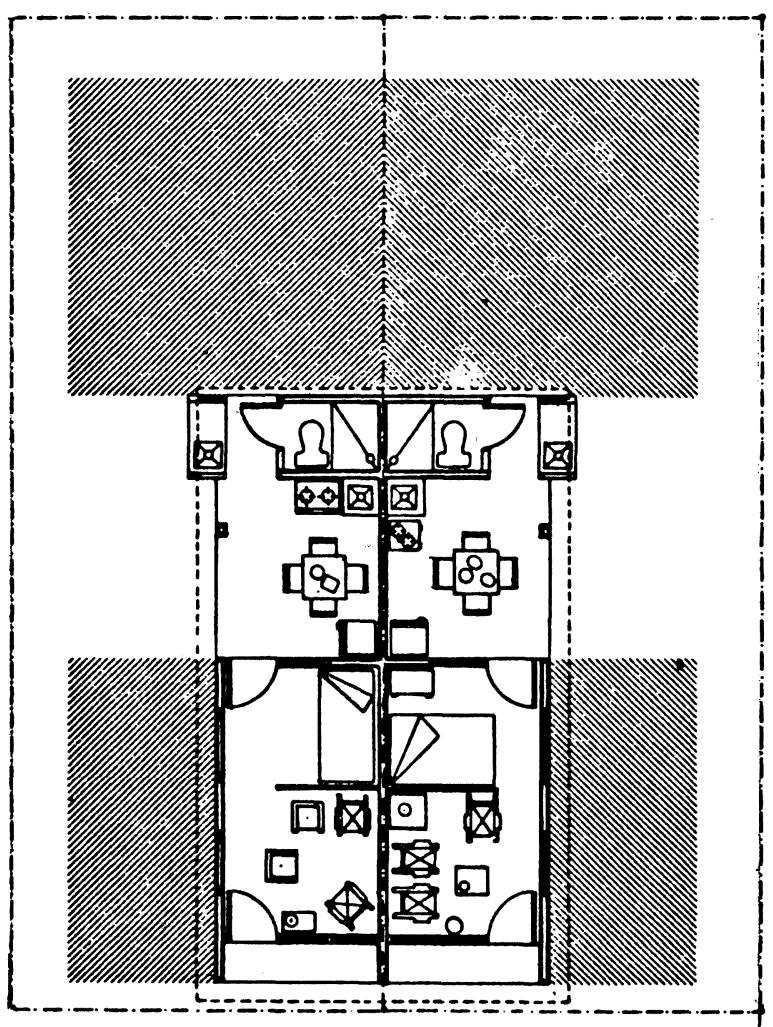

ETAPA 3

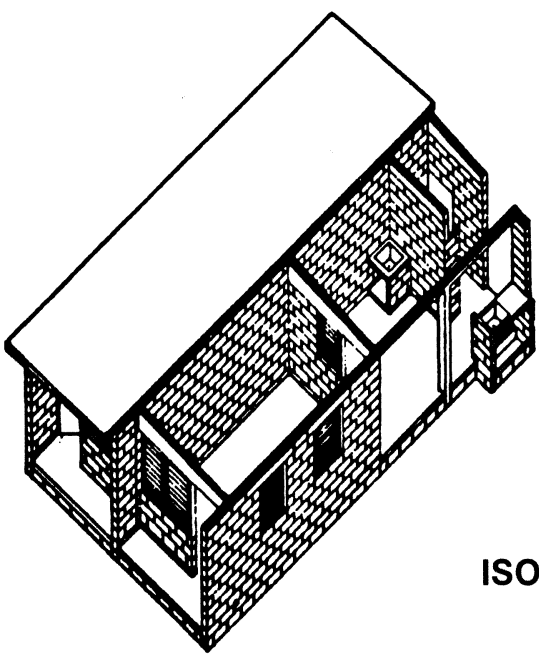

ISOMETRICA

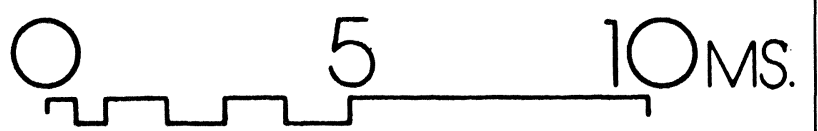

MODELO A

Plano n. ${ }^{\circ} 6$

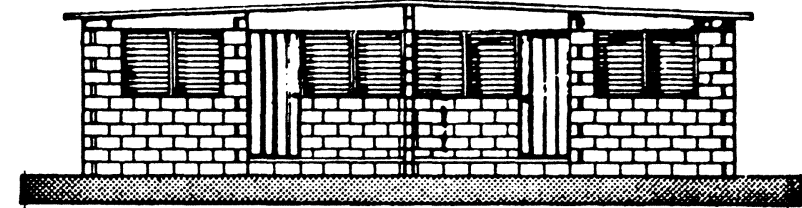

ELEVACION CENTRAL
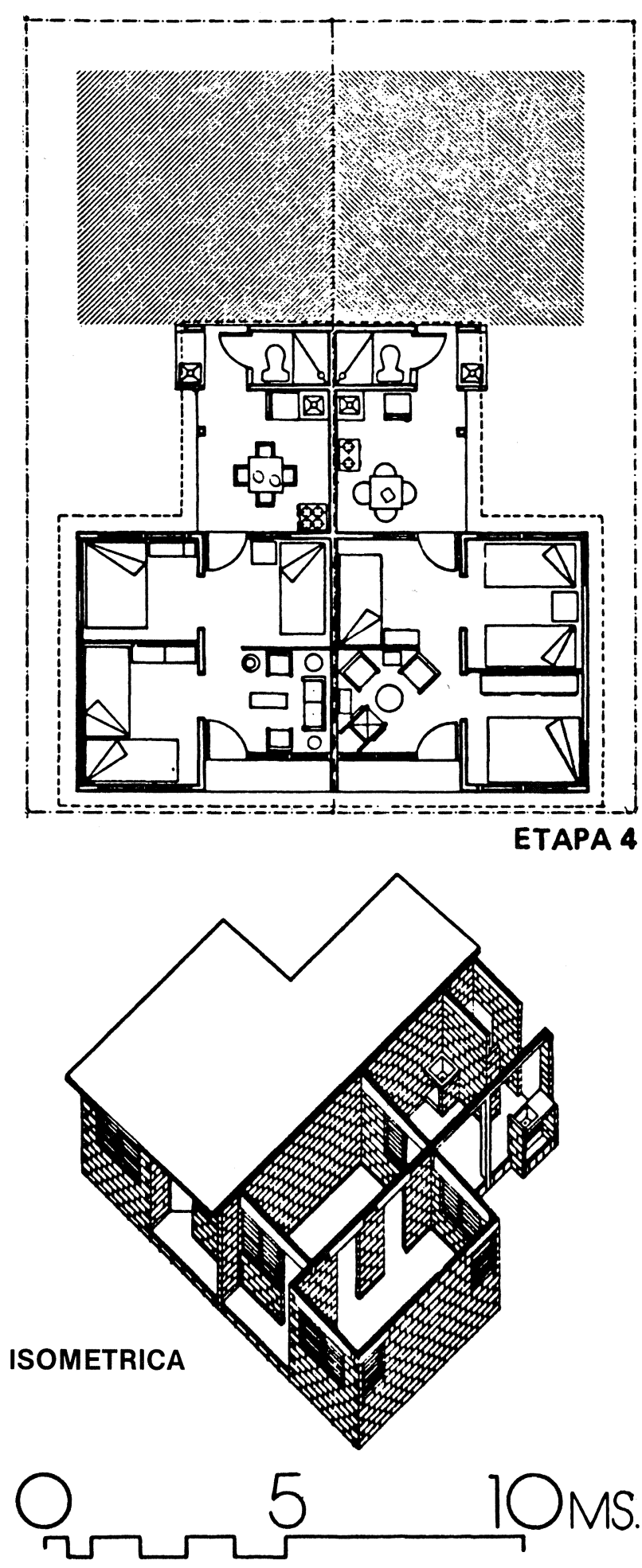

Plano $n .^{\circ} 7$ 


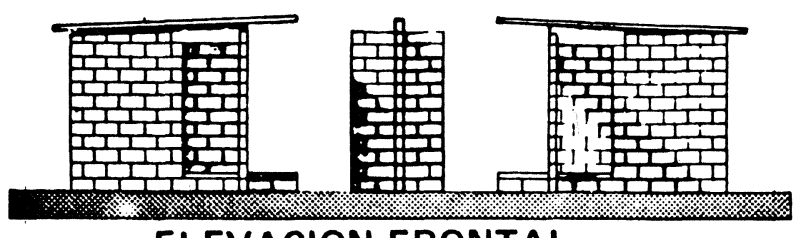

ELEVACION FRONTAL

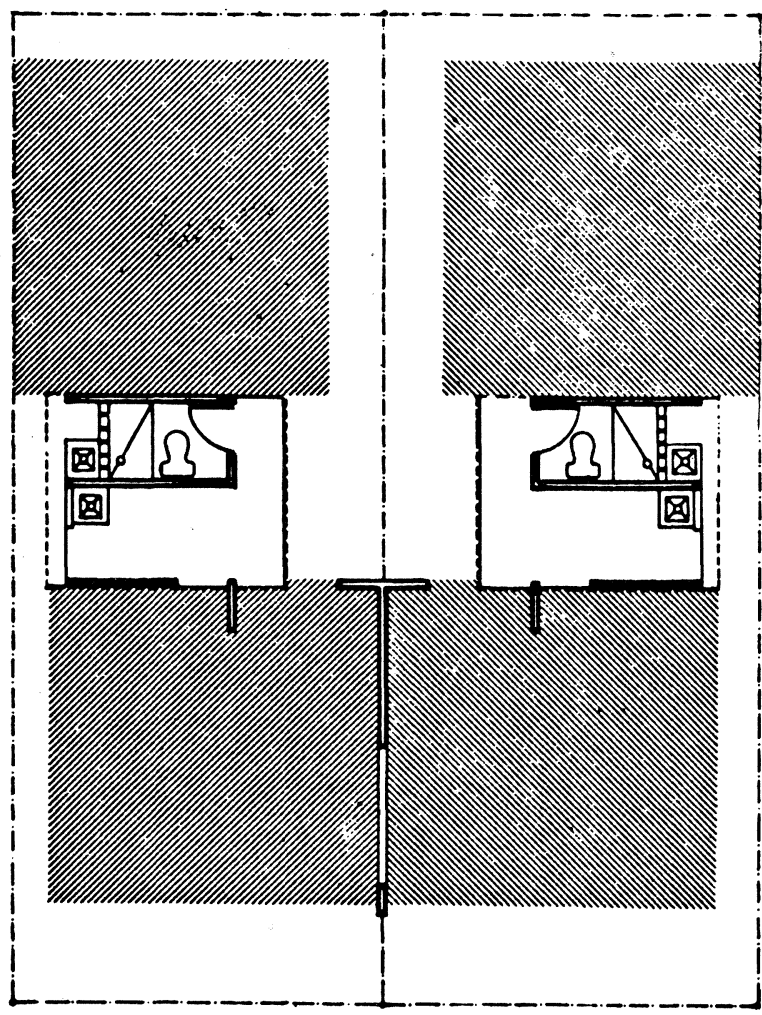

PLANTA

ETAPA 1
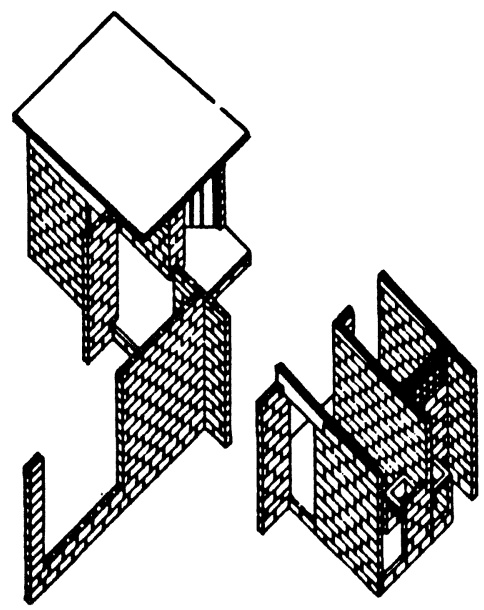

ISOMETRICA

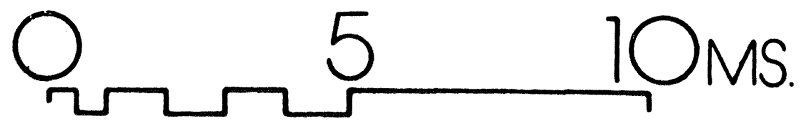

MODELO B
Plano n. ${ }^{\circ} 8$

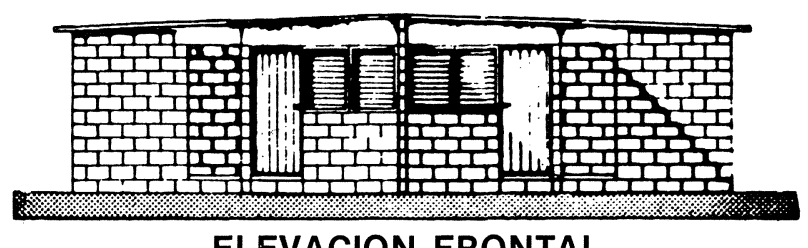

ELEVACION FRONTAL
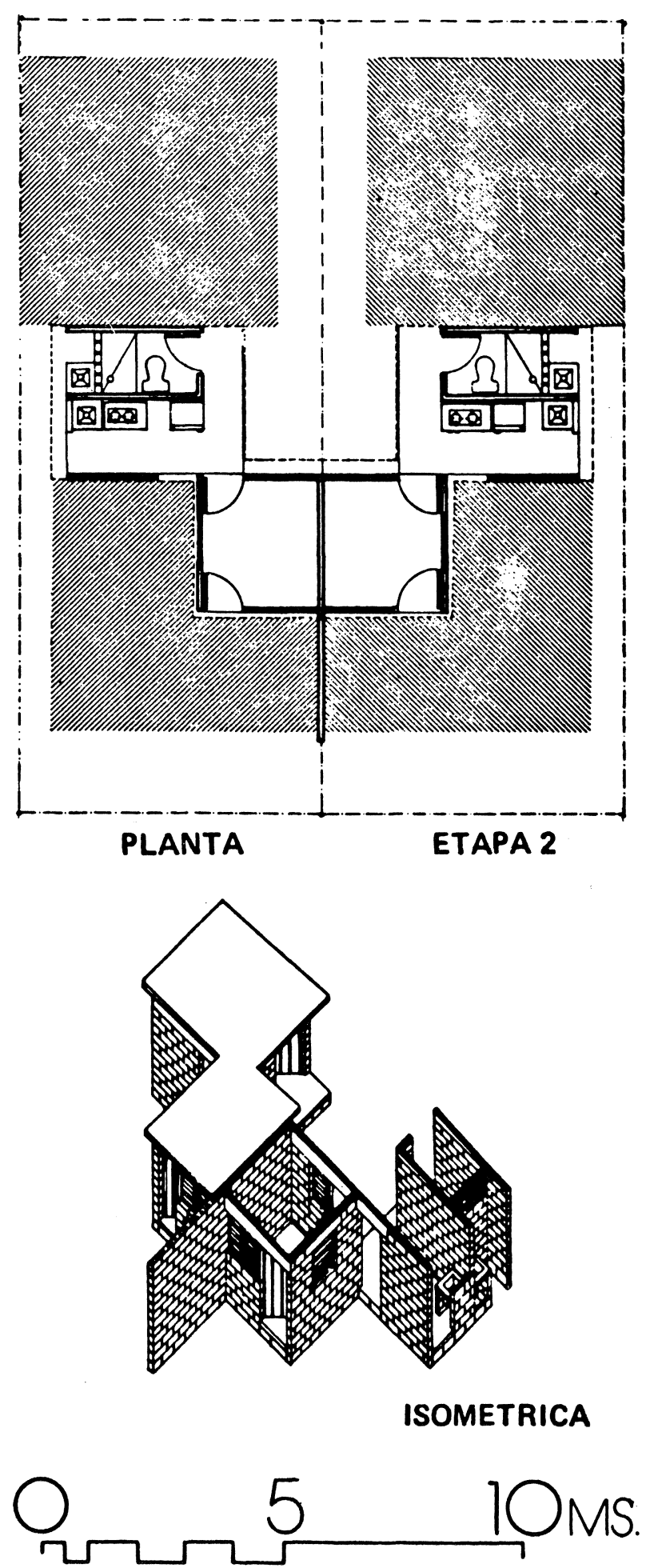

Plano n. ${ }^{\circ} 9$ 

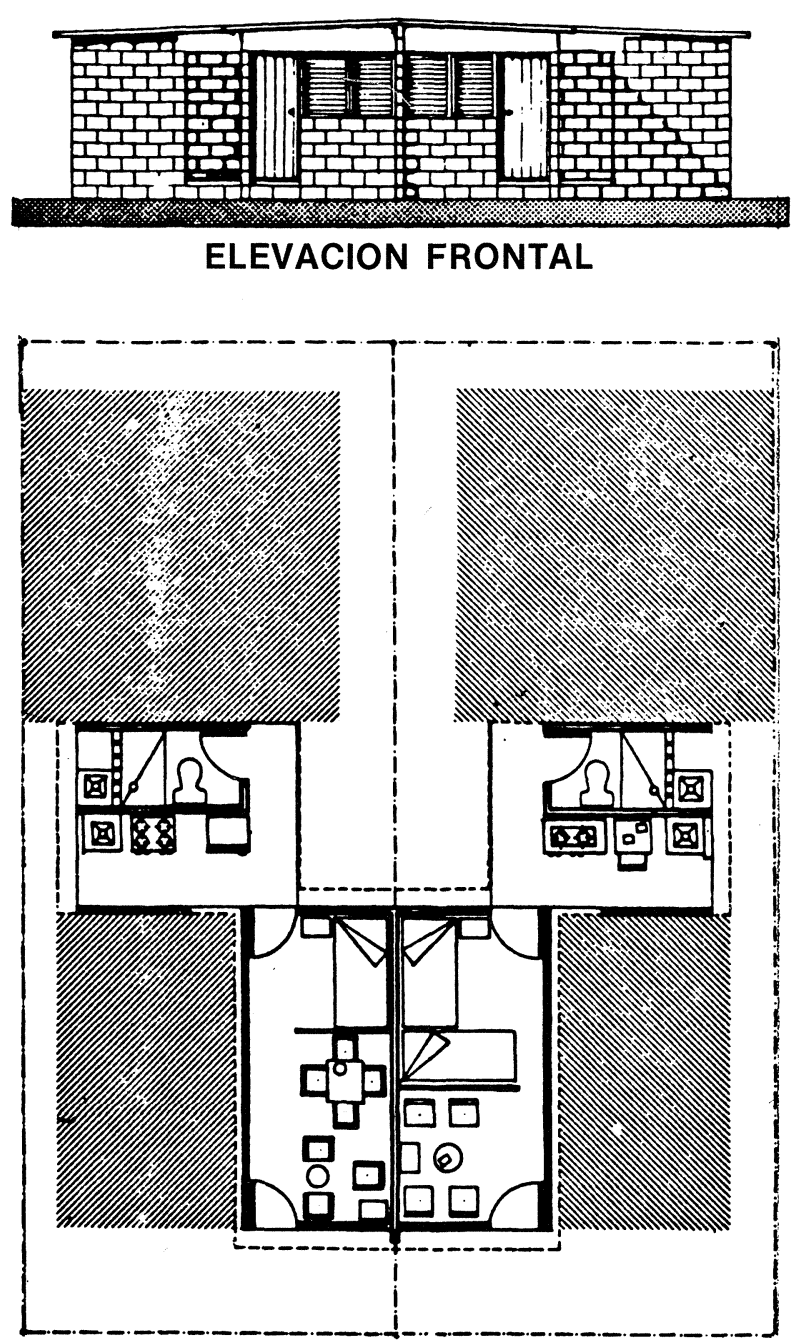

ETAPA 3
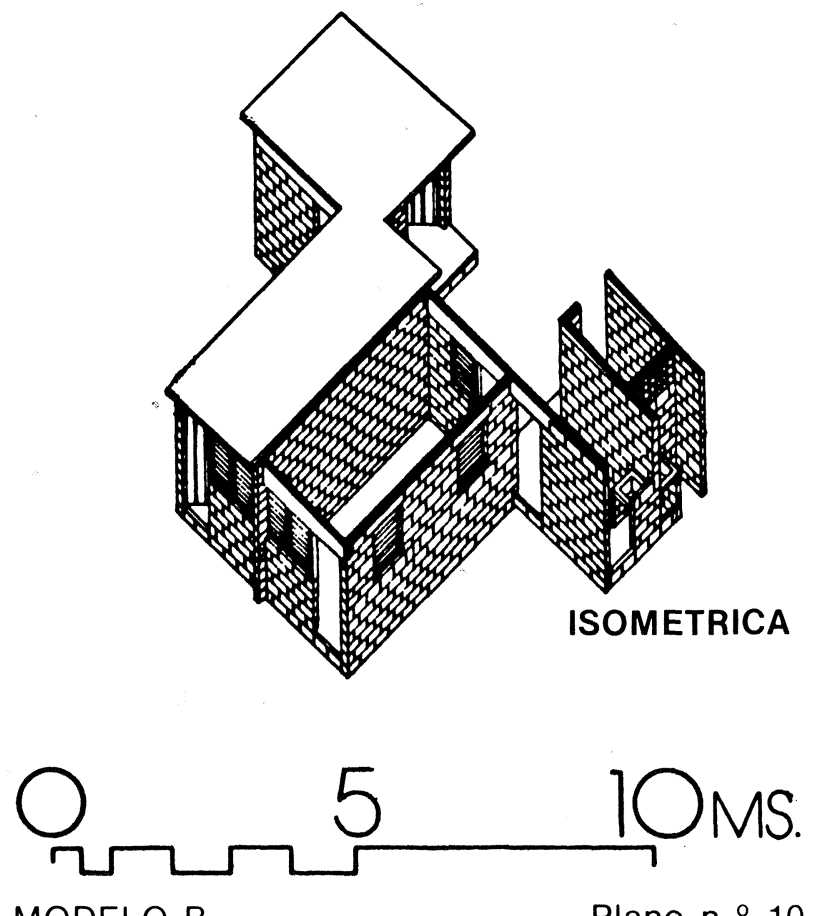

Plano $n .^{\circ} 10$

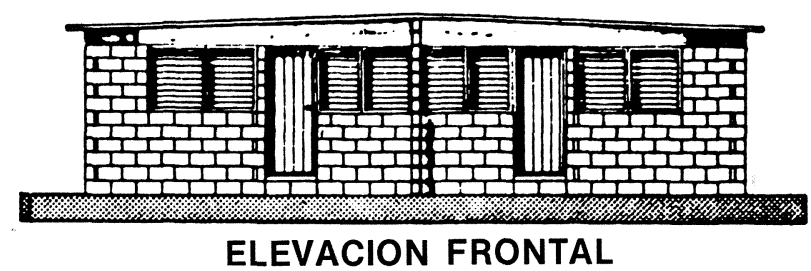

ELEVACION FRONTAL

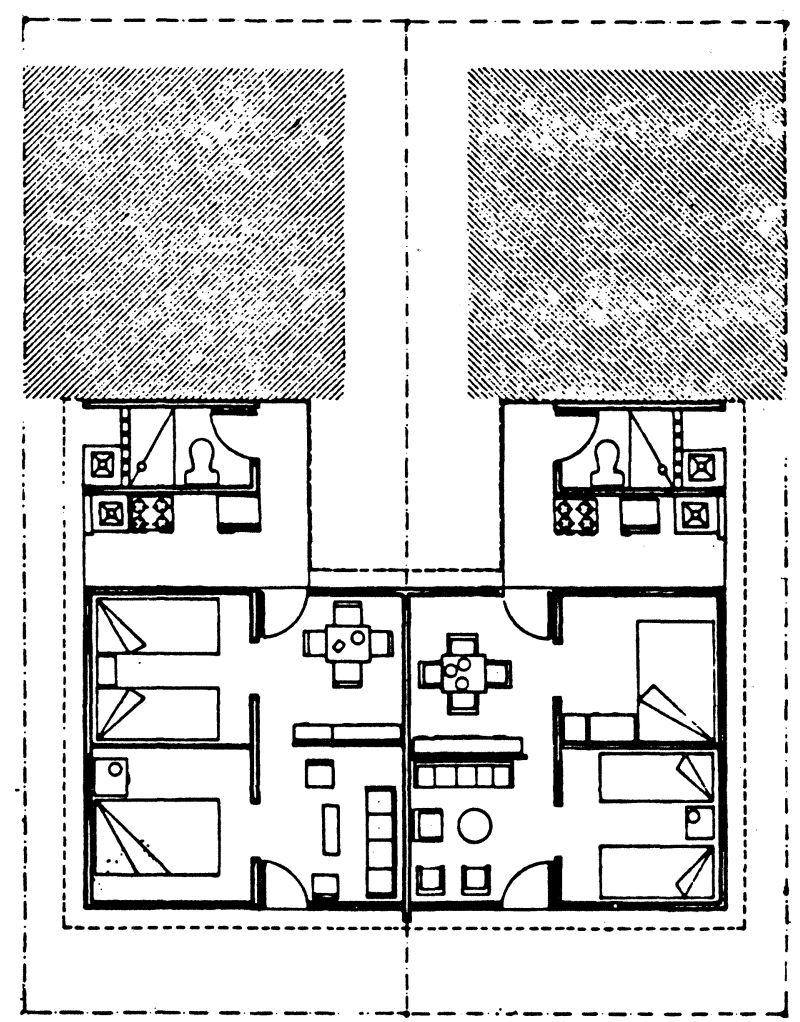

ETAPA 4

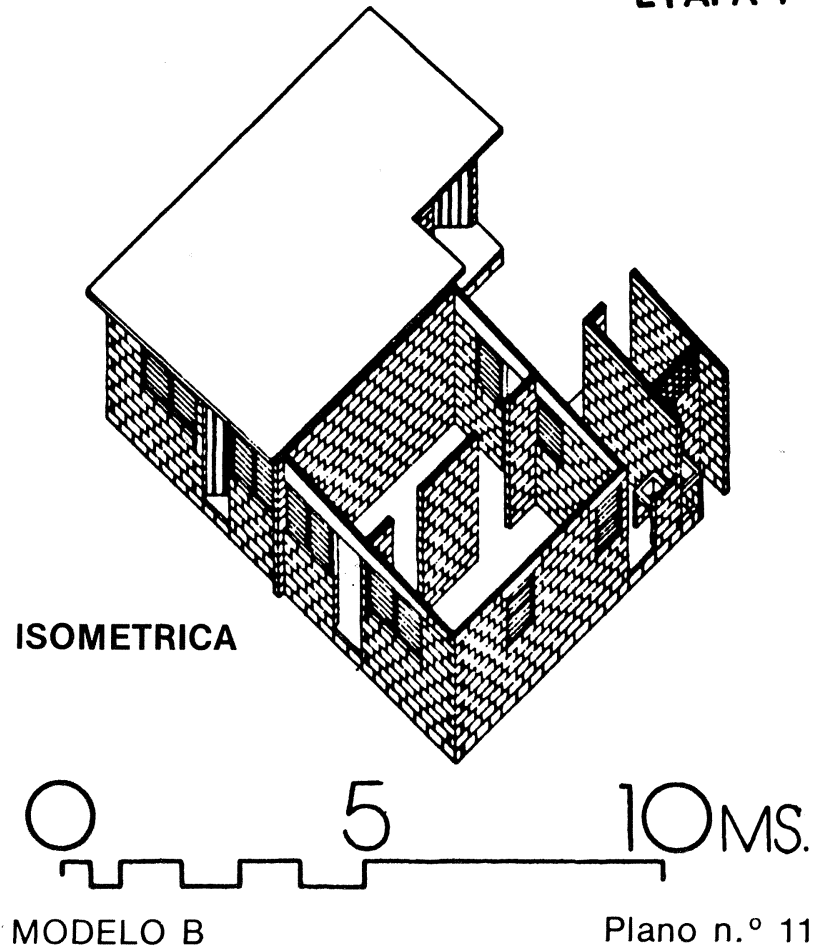




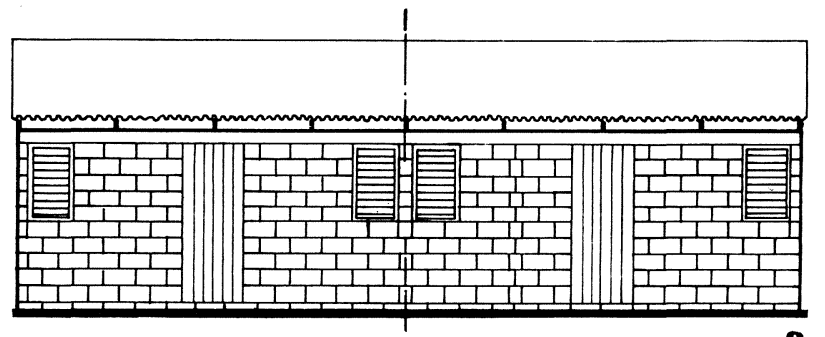

ELEVACION FRONTAL

25 บTS $^{2}$
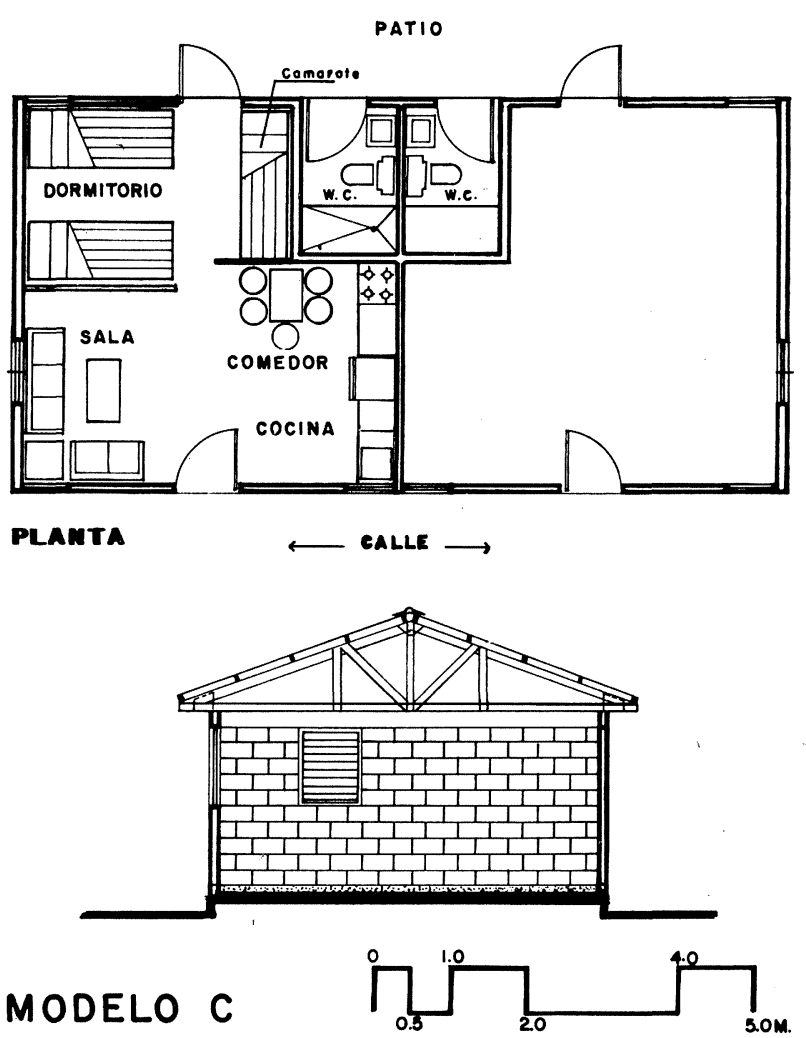

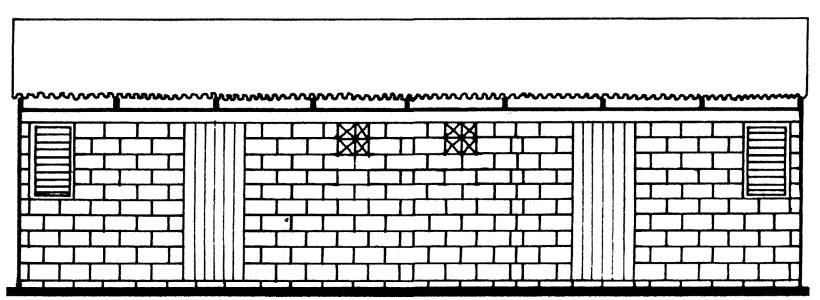

ELEVACION FRONTAL 25 MTS. $^{2}$
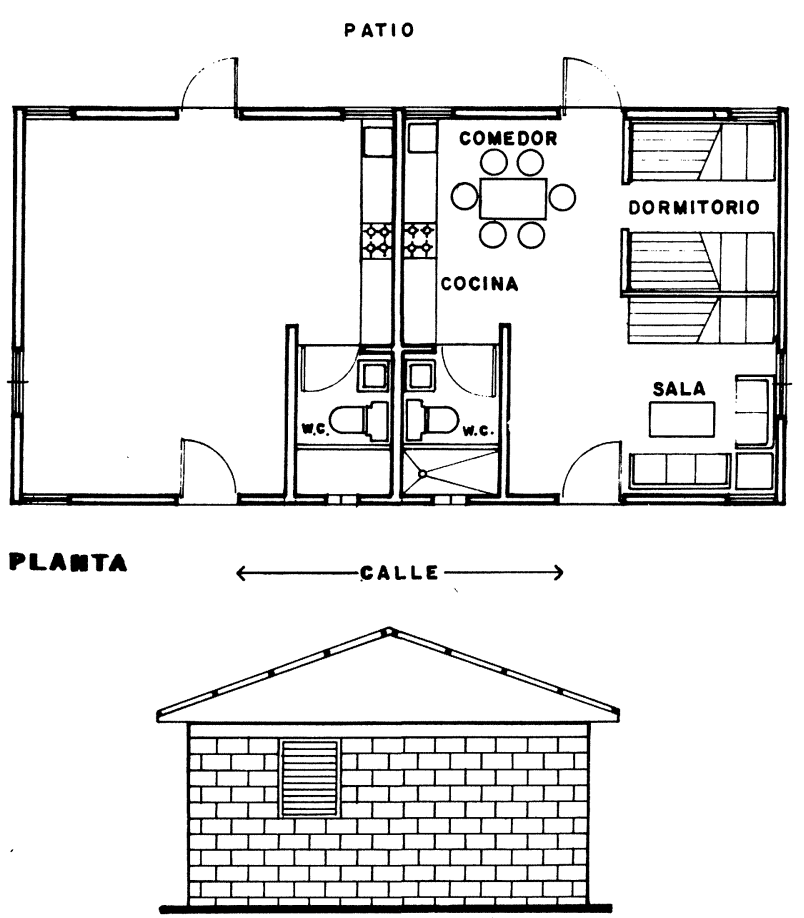

ELEVACION LATERAL DERECHA

\section{MODELO D}

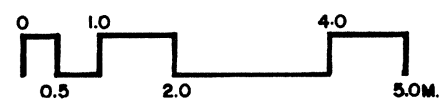

Plano n. ${ }^{\circ} 12$

\section{ETAPA 4}

Tiene $39,40 \mathrm{~m}^{2}$ de construcción y una ocupación del terreno de $38,6 \%$. Presenta la unidad sanitaria, sala, comedor y área de dormitorios que podrá ser dividida de diferentes maneras.

La vivienda completa a la que este modelo puede llegar, puede tener unos $72 \mathrm{~m}^{2}$ construidos, con un $71 \%$ de ocupación del terreno. Al igual que en el Modelo "A", en ésta se adiciona el módulo trasero.

Los aspectos que se presentan son: Unidad básica, sala, comedor, dormitorios, área multi-uso.

\section{MODELOS «C» $y$ «D»}

Estos modelos de viviendas pareadas tienen un área de $25 \mathrm{~m}^{2}$ techada con muros exteriores y $\mathrm{s}$ in divisiones interiores. Presentan la unidad sanitaria y la cocina.

La flexibilidad en la planta, permite dividir los ambientes diurnos y nocturnos de diferentes maneras: Sala-comedor, y área de dormitorios.

El diseño de esta vivienda, está concedido de tal forma que, permita la progresión futura hacia el patio, asi como posibilidades de autoconstrucción. Además la solución permite la habitabilidad inmediata de la familia en la misma. El modelo $C$, tiene el baño hacia el patio y el Modelo $D$ presenta la unidad de baño hacia la calle.

\section{MODELO «E»}

Tiene una superficie de $10 \mathrm{~m}^{2}$ cubiertos. La unidad sanitaria compuesta de ducha, inodoro, lavamano, fregadero y una pequeña zona de resguardo. 


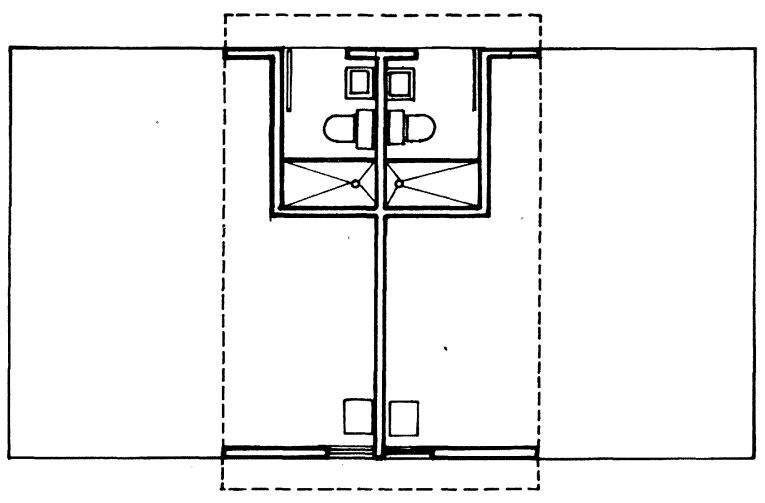

SOLUCION E ( 10.00 MTS $^{2}$ CUBIERTOS)
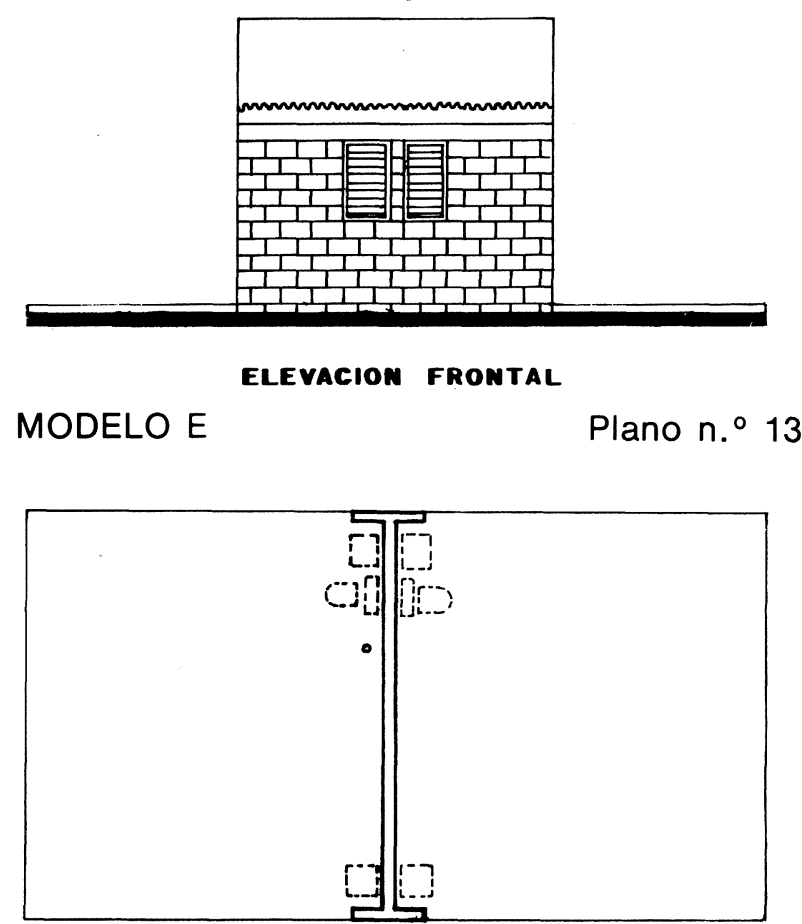

PARED SANITARIA

MODELO F

Plano n. ${ }^{\circ} 14$

A fin de facilitar la inmediata ocupación de la vivienda, se entrega una platea o losa de piso de $25 \mathrm{~m}^{2}$ para que las familias puedan instalarse de inmediato, previa construcción de una vivienda provisoria realizada por ellos mismos o traslado de los tabiques o muros que tengan en la vivienda actual donde están viviendo.

\section{MODELO «F»}

Tiene un muro sanitario con salidas de servicios para la instalación de los mismos en un futuro: Ducha, inodoro, lavamanos y fregadero. Además, una platea (o losa de piso) de $25 \mathrm{~m}^{2}$ para que cumpla los mismos objetivos señalados en el Modelo "E».
En los tres modelos antes señalados (C, D, E y $F$ ), se ha partido del supuesto que debe entregarse a las familias, unas soluciones minimas en la cual puedan instalarse tan pronto les sea entregado la parcela. Para la posterior terminación de la solución habitacional, se ha pensado en el sistema de autoconstrucción o esfuerzo propio.

En este contexto, se entregará como mínimo a las familias las instalaciones sanitarias (agua potable y drenaje), las acometidas eléctricas y el muro sanitario. Todas estas construcciones sobre una platea (o losa de piso) de $25 \mathrm{~m}^{2}$ - perfectamente terminada y con la cimentación más adecuada a los diferentes tipos de suelo.

Además, se ha propuesto la utilización de materiales conocidos por los sectores populares, por ejemplo, se ha proyectado los muros en base a bloques de hormigón y la techumbre con cubierta de planchas de zinc, sobre tijerillas (cerchas) de madera. Ambos materiales el bloque y el zinc, son manejados con verdadera habilidad por los pobladores no técnicos del sector informal. En estos sectores informales, más del $80 \%$ de las viviendas urbanas, están cubiertas con zinc.

Las cerchas que conforman la estructura del techo son muy simples y pueden ser fácilmente preparadas por usuarios no técnicos en la construcción, se utilizan escuadrias mínimas y sólo clavos para la unión de las piezas de madera. Por lo demás, resulta más económico este tipo de techo que el de losa de hormigón o canaleta de asbesto-cemento.

Creemos que con estos planteamientos el INVI puede llevar adelante un amplio programa de autoconstrucción, recuérdese que se trata de un proyecto de más de 4.600 parcelas. Se está implementando también, una cartilla de Esfuerzo Propio que se entregará a los usuarios, para que con la supervisión necesaria, terminen sus viviendas o las amplien.

Consideramos que estos materiales pueden no ser los óptimos y que puede y debe haber alternativas, principalmente pensando en los sectores rurales. Pero repetimos, se han propuesto en consideración al gran conocimiento que tienen de ellos los sectores populares.

Sin embargo, cabe hacer notar que desde hace cuatro años, el INVI está participando en programas de investigación de tecnologias apropiadas y tecnologias propias (conjuntamente) con CETAVIP, Centro de Tecnología Apropiada para la Vivienda Popular) y uso de nuevos materiales. También se está desarrollando pequeños programas de autoconstrucción en zonas rurales cercanas a la capital, a través de una oficina técnica especializada PDIPC (Proyecto Desarrollo Integral de Pequeñas Comunidades), la cual ha probado techumbres de sisal-cemento, muros de adobe, de suelo cemento y hormigón ciclópeo. 
Existe también el interés de estudiar y desarrollar técnicas constructivas basadas en el bagazo de caña, hormigón en base a desperdicios orgánicos, el bambú, la caña y la yagua (hojas de palmas utilizadas por los campesinos en sus viviendas), estructura de horcones, etc.

Al entregarse la vivienda terminada, sólo con sus muros perimetrales y sin divisiones interiores, se hace indispensable instruir a los usuarios y ojalá organizarlos para que logren en forma económica y racional producir tabiques y muebles. Existe la idea de convocar a concursos nacionales para los proyectos de camarotes (literas) muebles de cocina, sala y comedor. Se estima que muchos de estos muebles paneles y closets (armarios), podrian realizarse en talleres artesanales manejados por la misma comunidad de usuarios.

Igualmente, hay interés en que el INVI haga un verdadero seguimiento a los proyectos, ya que si las familias no cuentan con apoyo posterior (técnico y crediticio), puede "arrabalizarse" rápidamente el barrio. Principalmente los sectores en los cuales sólo se ha entregado la pared sanitaria. Creemos que cada familia debe tener el máximo de libertad para terminar su vivienda, ampliarla o desarrollarla como mejor le parezca o como mejor pueda, sin perder su identidad.

En República Dominicana, existen muy significativos ejemplos de arquitectura popular, con verdaderos aportes de color y detalles técnicos que provocan buenas soluciones de ventilación e iluminación.

\section{AUTORES DE LOS PROYECTOS}

En los acuerdos con el Banco Mundial se estipulaba la formación de una oficina especial para el desarrollo de los proyectos. Desde la iniciación del programa (en 1980 y hasta 1982) estuvo a cargo del Ing. Gustavo Toca y sus principales integrantes fueron los Arquitectos Enrique Garcia Pecci, Simón López, Roxanna Pina de Molina, Lic René Jáquez y el Ingeniero Oscar Navarrete.
A fin de abaratar los costos e incorporar el proceso de autoconstrucción por Esfuerzo Propio, la actual directiva del INVI ha encargado a los profesionales de la DIPRO (División de Proyectos), el estudio de nuevas soluciones de unidades habitacionales. Se ha desarrollado las soluciones habitacionales tipo $C, D, E$ y $F$ y se espera, a través del uso de una cartilla para los usuarios poder realizar programas de autoconstrucciión que permitan el acceso a las parcelas a un mayor número de familias de muy bajos recursos. El alza de los materiales y de la construcción en general, ha sido significativo y sólo un pequeño porcentaje de la población tiene posibilidades de acceso a una parcela con servicios.

El jefe de la DIPRO, es el Arquitecto Carlos A. Pou Howley y en el proyecto de las mencionadas soluciones han participado, además de los Arquitectos e Ingenieros de esa División, los profesionales de la PDIPC. Han estado a cargo de los proyectos, los Arquitectos Aracelis Jiménez B, y Roxanna Pina de Molina y se ha contado con la asesoría del Proyecto de las Naciones Unidas CNUAH-HABITAT DOM.81/003, a través de los Arquitectos Oscar Cortés y Oscar Barahona.

\section{BIBLIOGRAFIA}

1. Proyectos Urbanos de Parcelas con Servicios Sabana Perdida y Haïna.

Instituto Nacional de la Vivienda

Ing. Gustavo Toca - Santo Domingo, junio de 1982.

2. Ponencia Ing. María Asunción Gatón Universidad Nacional de Colombia Programa Estudio de Viviendas Económicas en América Latina (PEVAL)

5to. Ciclo de Talleres. Medellin, septiembre de 1984.

3. Diagnóstico del Sector Habitacional - Oficina de la Vivienda AID - Washington, Abril de 1980.

4. República Dominicana en Cifras 1983. Secretariado Técnico de la Presidencia, mayo de 1983.

5. Grandes Conjuntos - Informes Técnicos - INVI-HABITAT Arq. Hiram Quiroga - Oscar Barahona. Santo Domingo, septiembre de 1983. 